\title{
Behavior of Particulate Matter Produced by Cars in a Regional Model of Urban Canopy Layer
}

\author{
J. Pospisil*, M. Jicha \\ Faculty of Mechanical Engineering, Brno University of Technology, Czech Republic \\ *Corresponding author: pospisil.j@fme.vutbr.cz
}

\begin{abstract}
This paper introduces the utilization of the CFD technique for the modeling of PM10 (particulate matter $10 \mu \mathrm{m}$ ) behavior in urban areas, focusing on a description of the processes in the ground surface boundary layer. A description of the deposition and resuspension processes is introduced and applied to the regional numerical model of the city of Brno. The threshold velocity of re-suspension was obtained from the small scale modeling of PM10 dispersion in a street gully located inside the regional model. The predicted concentration fields were compared with theoretical studies and an in-situ measurement.
\end{abstract}

KEY WORDS: particulate matter, numerical modeling, urban area

\section{INTRODUCTION}

The increase of the PM (particulate matter) concentration level in cities stimulates an intensive research focused on a better understanding of particles behavior during their lifetime period in urban areas. The highest concentrations of PM are generally present in the inner parts of urban areas, specifically at a close vicinity to major traffic paths. Many parameters influence the formation, transport and deposition of particles at these locations. The particle's behavior is influenced by transportation in moving air, settling due to gravity, interaction with buildings walls, deposition on a ground surface and re-suspension of once deposited particles that are lifted by a local air movement and dispersed into surroundings. Therefore, a particle's behavior is a very complex process difficult for an accurate mathematical description. The numerical models for the prediction of PM concentration fields in urban areas fall into two categories: i) a detailed solution of PM dispersion processes with simplified quantification of PM sources (Fleming, 2003) and ii) a solution of concentration fields for gas species $\left(\mathrm{NO}_{\mathrm{x}}\right)$ with a known correlation to PM (Kukkonen et al., 2001). The CFD modeling falls into both groups and represents the only tool capable to take into account the detailed geometry of urban areas and the interaction between moving cars and ambient air (Jicha et al., 2000). Numerical models of large areas are necessary for a correct description of long-distance PM10 transport. On the other hand, small scale models are necessary for a detailed prediction of PM concentrations in the close vicinity of traffic paths. The encasing of both types of numerical models enables a correct, complex and effective numerical prediction of PM concentration fields. It is impossible to accurately quantify the production of all real PM sources in urban areas. In this study we focus on the sources directly connected with car movement on traffic paths and the flow conditions of the ground surface boundary layer, namely deposition and re-suspension. Re-suspension represents the most intensive source of PM10 in large urban areas. Particles spend a long time in urban areas and travel over long distances. The deposition is one of the major possible 
ways of separation of PM10 from the lower part of the atmosphere. In numerical models of urban areas the deposition is considered to be a sink of PM10 (negative source).

\section{MATHEMATICAL DESCRIPTION OF PARTICLE BEHAVIOUR}

\section{Particle deposition}

Deposition occurs on all solid and liquid surfaces located in a polluted atmosphere. The particle's deposition in a boundary layer is described with the inclusion of turbulent transport and particle settling (Csanady, 1973)

$$
F=K \frac{d C}{d z}+v_{S} C,
$$

where $v_{s}$ is the settling velocity of the particles, $K$ is the eddy diffusivity for the mass transfer of the species with the concentration $C$, and $F$ is the downward mass flux.

The eddy diffusivity is correctly solved by the CFD technique in a fully turbulent flow. Wall functions substitute the accurate solution of eddy diffusivity in surface boundary layers. Close to the surface, the eddy diffusivity is nearly zero. The Brownian diffusivity of particles greater than $1 \mu \mathrm{m}$ is near to zero too. The downdraft mass flux is then controlled by the deposition velocity calculated as (Simpson et al., 2003)

$$
v_{S}=\frac{D_{p}^{2} \rho_{p} g C_{C}}{18 \mu}
$$

where Dp and $\rho_{\mathrm{p}}$ are respectively the particle diameter and density, $\mu$ is the air dynamic viscosity, $g$ is the gravitational acceleration. $C_{c}$ is the slip correction factor expressed as

$$
C_{C}=1+\frac{2 \lambda}{d_{p}}\left[1.257+0.4 \exp \left(-\frac{1.1 d p}{2 \lambda}\right)\right]
$$

where $\lambda$ is the mean free path of gas molecules.

\section{Particle re-suspension}

From different studies it follows that the re-suspension of once deposited particles is the most intensive source of urban airborne particles during "dry periods". The re-suspension process of once deposited particles depends on an actual air velocity field above the ground surface, alocal slit load, a surface roughness, particle geometry and other particle parameters. Coarse particles $(\mathrm{d}>2.5 \mu \mathrm{m})$ are very often able to be re-suspended from dry-surfaces. On the other hand, fine particles and ultra fine particles show only a limited tendency of re-suspension from all surfaces. This results from the significant amount of a liquid fraction forming particles smaller than $2.5 \mu \mathrm{m}$ and existence of the Van der Waals force between ultra-fine particles and surfaces. Re-suspension of particles is generally impossible from wet and adhesive surfaces. From the above mentioned follows that the re-suspension process is very complex and its mathematical description is generally connected with a high value of uncertainty. The re-suspension of particles settled on surfaces results from the interaction of aerodynamic, electrostatic and mechanical forces, see fig. 1. 


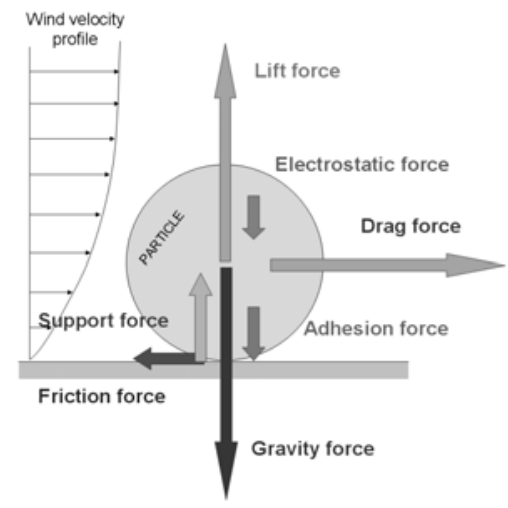

Figure 1: Particle interaction of aerodynamic, electrostatic and mechanical forces

The Saffman lift force due to a velocity gradient near walls is an important aerodynamic interaction. This lift force is oriented perpendicularly to the direction of flow affecting deposited particles in a viscous fluid. An electrostatic force on the charged particles can be calculated only for the known particle charge and the magnitude of the electrical field. This information is not common for dispersion studies and the electrostatic force is commonly excluded from calculations. The Saffman lift force and the fluid turbulence are sufficient to suspend fine and ultra fine particles. Coarse particles are often moved by the drag force along the surface. The turbulent intensity of a stream can also influence the air drag force affecting particles. The drag force affecting particles in a boundary layer was expressed in the form (Punjrath et al., 1972)

$$
F_{d}=\frac{\pi d^{2} C_{f x} \rho U^{2}}{8}
$$

where $C_{f x}$ is the local shear stress coefficient, $\rho$ is the air density, and $U$ is the free-stream air flow velocity. An irregular shape of particles, together with a surface roughness, cause irregular bouncing of the particle against walls. This behavior prepares good conditions for the following up lift of particles in a boundary flow. Various forms of equations can be found in literature for determination of the windblown dust flux. Algorithms solve the dust flux either from the wind velocity and the threshold wind velocity (5) (Tegen and Fung, 1994) or from the friction velocity and the threshold friction velocity (6) (Claiborn et al., 1998)

$$
F=C_{T F} u^{2}\left(u-u_{t}\right) \text {, }
$$

where $F$ is the dust flux, $u$ is the wind velocity, $u_{t}$ is the threshold wind velocity and $C_{T F}$ is the constant representing the character of the soil surface (disturbed/undisturbed).

$$
F=C u_{*}^{3} a_{g}\left(u_{*}-u_{* t}\right) \text {, }
$$

where $a_{g}$ is the constant expressing the effect of non-instantaneous wind velocity $(\sim 1.2)$, $u^{*}$ is the friction velocity, $u^{*}{ }_{t}$ is the threshold friction velocity and $C$ is an empirical constant.

The friction velocity for a neutrally stable atmosphere can be determined in a couple of ways. From the logarithmic wind velocity profile, the wind velocity is related to the friction velocity as

$$
u=\frac{u_{*}}{k} \ln \left(\frac{z-d}{z_{0}}\right),
$$


where $k$ is the von Karman constant $(\sim 0.4), z_{0}$ is the aerodynamic roughness length and $d$ is the displacement height.

The wind velocity of re-suspension is the lowest velocity of air at height $10 \mathrm{~m}$ above the ground, for which re-suspension represents a significant contribution in an urban air PM10 concentration. The wind threshold velocity of re-suspension is strongly influenced by an actual geometry of an urban area, air density and the geometry of particles. From studies carried out, the corresponding urban threshold velocity of re-suspension is $2.4 \mathrm{~m}$ for the studied area. The previous paragraph discussed the wind threshold velocity of resuspension with the utilization of the driving wind velocity above the "building's roof" level. But numerical models describing processes in a boundary layer require a much more detailed approach to the correct description of re-suspension. For this reason, we focused on a particular street gully in the city of Brno. The numerical model of the studied gully was built up. A series of calculations were carried out with the focus on a detailed description of an air flow above the ground and road surface. We considered spherical particles with a diameter of $10 \mu \mathrm{m}$, a density of particles $1200 \mathrm{~kg} / \mathrm{m}^{3}$, a parametrical roughness of surface $0.0003 \mathrm{~m}$ and a wind profile displacement $0 \mathrm{~m}$. The street gully threshold velocity of re-suspension was determined as $0.75 \mathrm{~m} / \mathrm{s}$ (at height $0.35 \mathrm{~m}$ ). Different studies on determination of the threshold velocity of particle re-suspension were carried out in recent years. The majority of these studies considered particle re-suspension from a flat horizontal surface that fits well to the detailed solution of a bottom part of the studied street gully. We compared the predicted street gully threshold velocity of re-suspension $0.75 \mathrm{~m} / \mathrm{s}$ with the results derived from formulations published by Cornelis and Gabriels (2004) and Saho \& Lu (2003). From the Cornelis and Gabriels (2004) formulation, we derived the threshold velocity of re-suspension $0.724 \mathrm{~m} / \mathrm{s}$. From the Saho and $\mathrm{Lu}$ (2003) formulation, we derived the threshold velocity of re suspension $0.957 \mathrm{~m} / \mathrm{s}$. The predicted street canyon threshold velocity of re-suspension for PM10 particles showed a good agreement with the above mentioned theoretical studies.

\section{A SIMPLIFIED DESCRIPTION OF PARTICLES DEPOSITION AND RE- SUSPENSION FLUXES}

It is impossible to accurately quantify the production of all real PM sources. Therefore, an appropriate simplification of the particle's production description is convenient for a numerical solution of PM concentration fields.

The simplification used in this study assumes the equivalence between the particle's deposition rate on smooth dry surfaces and the particle's re-suspension rate from these surfaces, influenced by wind velocity higher than the threshold velocity of re-suspension. Stable deposition is assumed on grassy surfaces and smooth dry surfaces influenced by wind velocity lower than the threshold velocity of re-suspension. The modified primary source term represents the only particles source term prescribed in the numerical model, see fig. 2. The modified primary source was assigned in the near road surface air layer, where the major amount of airborne particles is generated. From this air layer, particles disperse into the surroundings.

\section{PM10 DISPERSION MODELING ON A REGIONAL SCALE MODEL}

The above mentioned description of deposition and re-suspension was utilized for PM10 dispersion modeling on a regional model. The regional solution domain involves 
the city of Brno and nearby surroundings. The solution domain covers an area of $12 \times 12 \mathrm{~km}$. Due to the large modeled area, it is impossible to accurately involve the geometry of all objects. The parametrical roughness is used as a convenient substitution of ground cover geometry. The primary ground surface was built up in accordance with the actual terrain profile. The regional model ground plan was divided into 576 square control regions with a side length of $500 \mathrm{~m}$. A convenient parametrical roughness was assigned within these regions. The ground cover was divided into seven groups that represent the most common ground covers in the studied area. The corresponding parametrical roughness values were derived for all considered ground covers: water surface, meadow, forest, separate buildings up to 3 floors high, continuous buildings in rows up to 3 floors high, separate buildings above 3 floors high, continuous buildings in rows above 3 floors high. The primary ground surface was refined at terminal control volumes size with the top view dimensions $50 \times 50 \mathrm{~m}$. The $900 \mathrm{~m}$ high air layer was modeled above the primary ground surface. This air layer was subdivided into 19 sub-layers. The lowest sub-layer height was $2.125 \mathrm{~m}$ and the highest sub-layer height was set to $100 \mathrm{~m}$.

\section{Traffic related PM sources}

The primary car exhaust emission factor is determined for a considered car fleet composition - diesel engines : petrol engines $=1: 3$. The particular emission factor values were derived from software MEFA v.02 (Mobile Emission Factors) published by the Ministry of Environment of the Czech Republic. The primary car exhaust emission factor value was determined as $0.0179 \mathrm{~g} / \mathrm{km}$ per car. A non-exhaust particle source related to traffic involves primary particles and the re-suspended particles. Primary non-exhaust particles are released from cars, tires and road surfaces. The emission factors of non-exhaust particles released from cars and tires can be derived from different studies. The amount of the primary road surface particles is a function of a road surface material and an actual road state. Re-suspended particles are silt road particles drawn up from a road surface. The re-suspension process intensity is fully dependant on an actual road silt load. The total PM10 emission factor is a sum of the exhaust particles emission factor and the non-exhaust emission factors. The average total PM emission factor of the regional model domain was derived from a previous study carried out in the studied area as $0.06265 \mathrm{~g} / \mathrm{km}$ car.

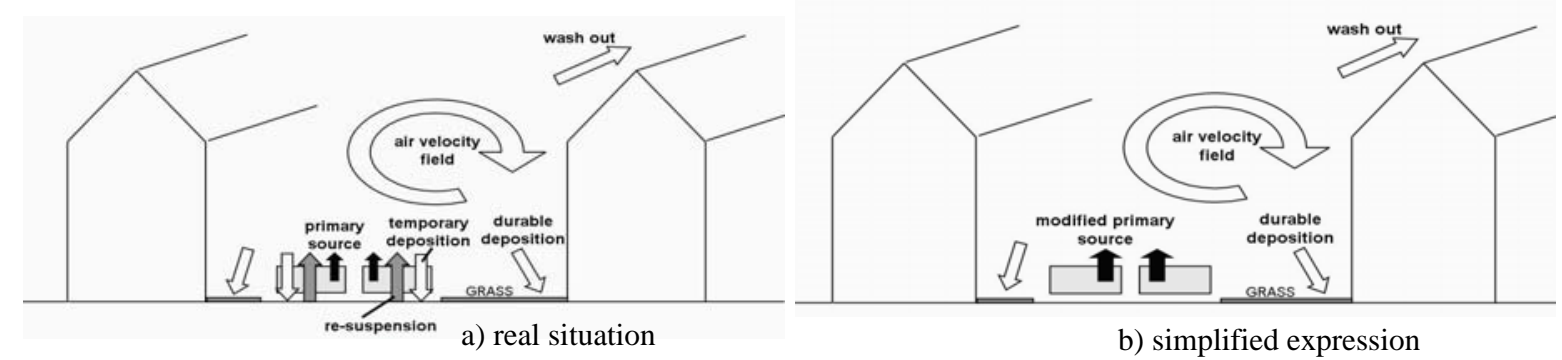

Figure 2: Particles fluxes in a street canyon

Corresponding traffic activity was derived from the Brno Transport Research Center database. Portions of traffic paths passing through individual control regions $(500 \times 500 \mathrm{~m})$ were specified. Traffic activity (car $\mathrm{km} /$ day) at traffic paths portions was multiplied by the total emission factor. The average total PM emission factor serves for the determination of the only particles source term prescribed in the numerical model. The source term was assigned at the air layer close to the ground surface, where a major quantity of airborne particles is generated. The inlet/outlet boundary conditions were assigned on the side walls of the regional model. The ground surface utilizes the wall boundary condition 
with an appropriate parametrical roughness. The top of the domain uses the condition of a wall with no friction. As a model of turbulence, a k- $\varepsilon$ RNG model was used.

\section{RESULTS AND DISCUSSION}

In the calculations, we presume coarse spherical particles with a diameter $10 \mu \mathrm{m}$. The density of the particles is set to $1200 \mathrm{~kg} / \mathrm{m}$-. Figure 3 shows the predicted PM10 concentration field obtained from the regional model for a wind velocity of $2 \mathrm{~m} / \mathrm{s}$ and 3 different wind directions. The cuts of concentration fields are led in a height of $3 \mathrm{~m}$ above the ground surface. The left column in Fig. 3 contains the concentration fields obtained from calculations without the inclusion of deposition. The right column shows the results with the inclusion of the deposition process. The inclusion of the deposition process decreases the PM10 concentration only by $1-4 \%$ in the central parts of the city due to small areas enabling a durable deposition. The decrease of PM10 concentration by $8-17 \%$ is observed in the residential areas of the city. The most intensive decrease in PM10 concentration occurs in the outskirts areas richly covered by greens and forests. The PM10 concentration fields show a higher concentration along roads with the highest traffic rate. At the bottom of the concentration fields, the inter-state highway passes around the city. Intensive traffic on this highway causes significantly higher PM10 concentrations along this traffic path. The regional background PM10 concentration of $15 \mu \mathrm{g} / \mathrm{m} 3$ was derived from a measurement carried out outside of the urban area. The north part of the city of Brno is without any intensive local sources of particles. This part of the city serves as residential areas without industry. The total predicted PM10 concentration is calculated as the sum of the predicted concentration and the regional background concentration. The result of this calculation is $23.5 \mu \mathrm{g} / \mathrm{m}^{3}$ at the position of the measurement located in the central part of the city. By our measurements, we obtained the PM10 concentration value $45 \mu \mathrm{g} / \mathrm{m}^{3}$.

\section{CONCLUSION}

The presented study shows the possible inclusion of deposition and re-suspension of PM10 particles in a regional scale dispersion model solved by the CFD technique. The CFD modeling represents a convenient tool for detailed PM dispersion modeling in urban areas. But the accuracy of these predictions is still limited due to the high uncertainty of PM source description and the limited possibilities for a correct description all physical processes. The predicted PM10 concentration field with the inclusion of the deposition and resuspension process represents $52.2 \%$ of the PM10 concentration value obtained from measurements in the central area of the city of Brno. The result shows that the predicted concentration values significantly underestimate the measured concentration values. The difference is probably caused by an intensive re-suspension of soil particles. This process is not taken into account in the numerical models due to difficult description of its source term.

\section{ACKNOWLEDGMENT}

The Czech Ministry of Transport financially supported this work under the grant $1 \mathrm{~F} 54 \mathrm{H} / 098 / 520$. 


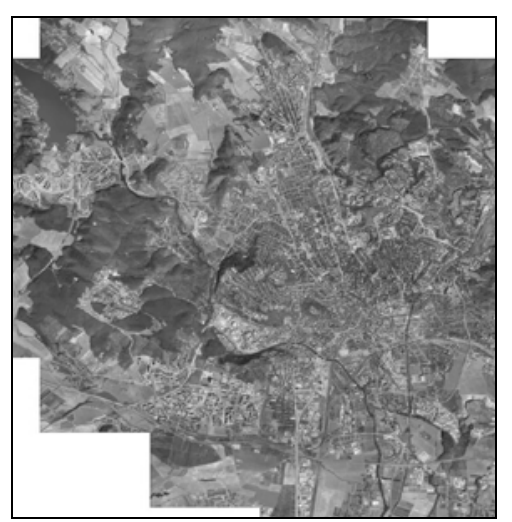

$\mathrm{PM} 10\left[\mathrm{~g} / \mathrm{m}^{3}\right]$

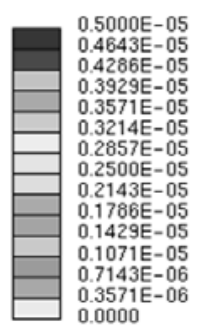

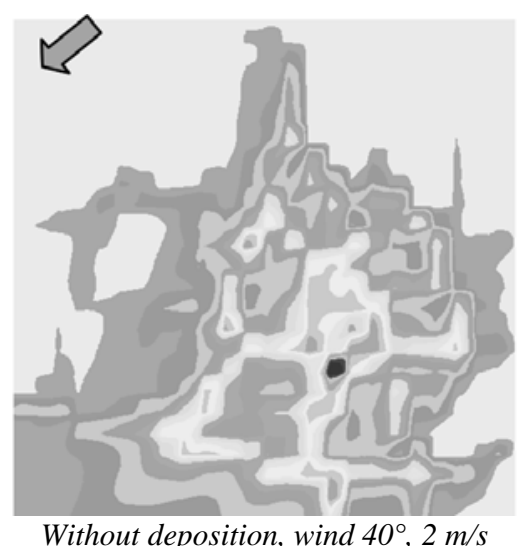

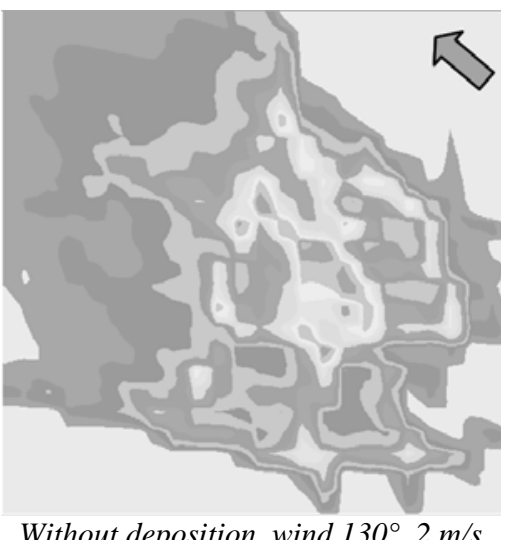

Without deposition, wind $130^{\circ}, 2 \mathrm{~m} / \mathrm{s}$

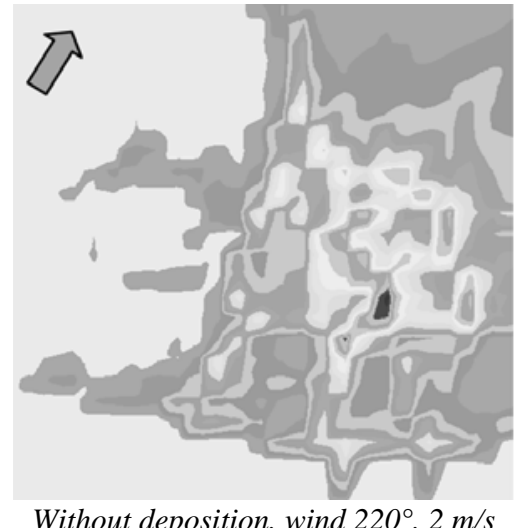

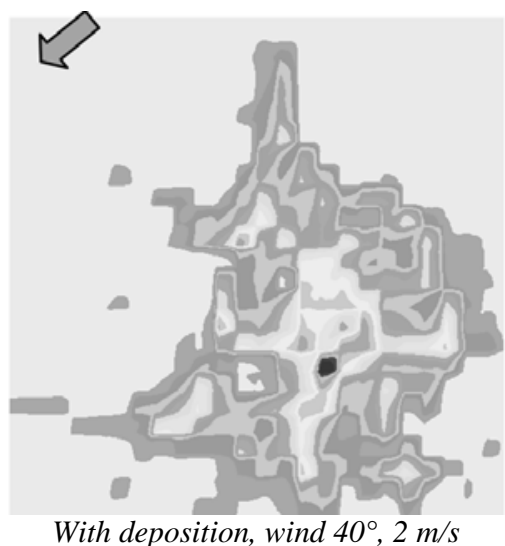

$\mathrm{PM} 10\left[\mathrm{~g} / \mathrm{m}^{s}\right]$
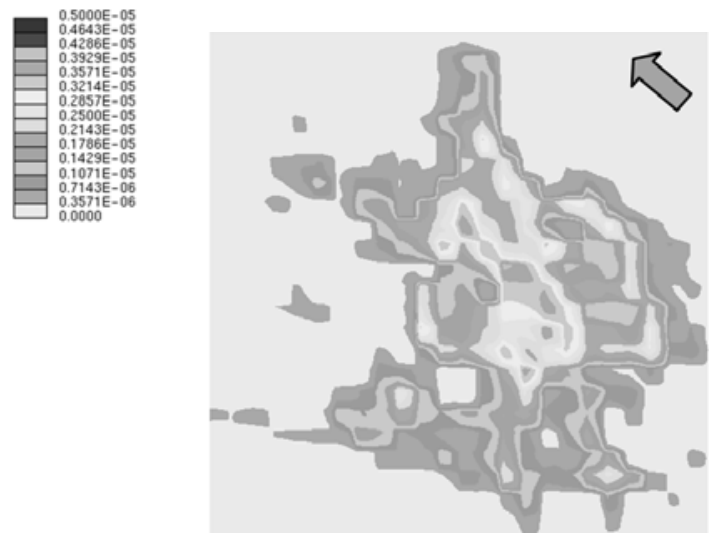

With deposition, wind $130^{\circ}, 2 \mathrm{~m} / \mathrm{s}$

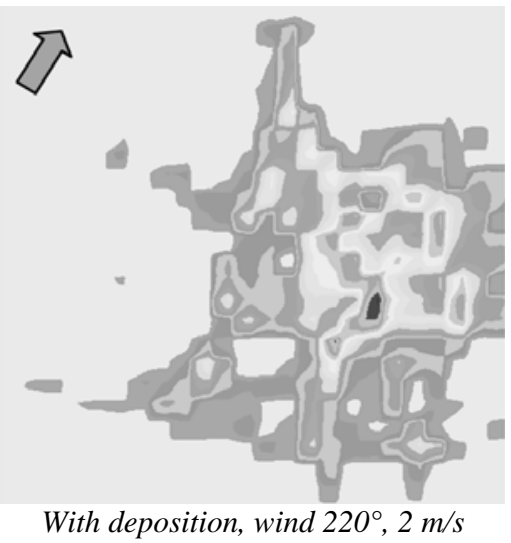

Figure 3: Predicted PM10 concentration fields led $3 \mathrm{~m}$ above ground surface 


\section{REFERENCES}

Claiborn, C.S., Lamb, B., Miller, A., Beseda, J., Clode, B., Vaughan, J., Kang, L., and Newvine, C. (1998) 'Regional measurements and modeling of windblown agricultural dust: The Columbia Plateau PM10 Program', J. Geophys. Res. 103, 19753 - 19768.

Cornelis W. M., Gabriels D and Hartmann R. (2004) 'A Parameterization for the Threshold Shear Velocity to Initiate Deflation of Dry and Wet Sediments', Geomorphology 59, pp. $43-51$.

Csanady G.T. (1973). Turbulent Diffusion in the Environment, Reidel, Dordrecht, Holland.

Flemming, J., 2003: Immisionsfelder aus Beobachtung, Modellirung und deren Kombinationen, Dissertation zur Erlangung des Doktoratgrades, Freie Universität Berlin.

Jícha M., Pospíšil J., Katolický J., 2000: Dispersion of pollution in street canyon under traffic induced flow and turbulence, Environmental monitoring and assessment, No. 65, pp. 343 351.

Kukkonen, J. et al., 2001: A semi-empirical model for urban PM10 concentrations, and its evaluation against data from an urban measurement network. Atmospheric Environment 35, pp. 4433 - 4442.

Moussiopoulos N. et al., 2003: Air Quality in Cities, Final Report of project SATURN: Subproject EURO-TRAC-2, ISBN 3-540-00842-x, Springer, Germany.

Punjrath J.S. and Heldman D. R., 1972: Mechanisms of small particle re-entrainment from flat surface, Aerosol Science, 3, pp. 429 - 440.

Saho Y and Lu H (2003) 'A simple expression for wind erosion threshold friction velocity', Journal of Geophysical Research 1005 (D17).

Simpson D., Fagerli H., Jonson J. E., Tsyro S. and Wind P. (2003), Unified EMEP Model Description - EMEP Status Report 1/2003, Norwegian Meteorological Institute.

Tegen, I. and Fung, I. (1994) 'Modeling of mineral dust in the atmosphere: Sources, transport, and optical thick-ness', Geophys. Res. Lett. 99, pp. 22897 - 22914. 